\title{
Kastamonu Yazma Eserler Kütüphanesinde Bulunan İki Adet Yazma Kur’an-ı Kerim Cüzünün Tezhip Sanatı Bakımından Değerlendirilmesi*
}

\author{
Evaluation of Two Qur'an Manuscript Sections at Kastamonu Manuscripts Library in \\ Regard to their Illuminations
}

\section{Yıldırım Karadeniz*}

\section{Öz}

Türkiye ve Dünya'daki kütüphaneler, müzeler ile özel kurum ve şahısların koleksiyonlarında bulunan el yazmaları, Türkİslam uygarlığıyla diğer uygarlıkların bilim, kültür ve sanat çevrelerini yakından ilgilendirmesi bakımından oldukça önemlidir. Yazmaların araştırılması ve incelenmesi konusu son yıllarda önem kazanmasına rağmen yine de çalışmalarda arzu edilen ilerleme sağlanamamıştır. Bu çalışmada, Kastamonu Yazma Eserler Kütüphanesi'nde bulunan 2161 ve 2163 envanter numaralı iki adet yazma Kur’an-ı Kerim cüzünün tezhip sanatı bakımından ele alınarak tanıtılması amaçlanmıştır. Kütüphanede bulunan cüzler tezhip özellikleri bakımından dikkat çekicidir. Cüzlerde görülen tezhiplerin benzer örnekleri 16. yüzyıl el yazmalarındaki tezhiplerde görülmektedir. El yazmalarında görülen tezhipler içinde cüzlerdeki surebaşı ve unvan sayfası tezhipleri önemli bir yer tutmaktadır. Bu bağlamda Kastamonu'daki cüzlerin çok kaliteli ve sanatsal aydınlatmaya sahip oldukları ve herhangi bir araştırmaya tabi tutulmadıkları görülmektedir. Makalede cüzler tezhip açısından incelenerek dönem özelliklerinin ortaya konulması amaçlanmaktadır.

\section{Anahtar Kelimeler}

Kastamonu, El yazması, Cüz, Kur’an-ı Kerim, Tezhip

\begin{abstract}
Manuscripts in libraries, museums, and collections of private institutions and individuals in Turkey and around the world are of great importance as they have a close connection with science, culture, and art circles of Turkish Islamic Civilization and other civilizations. Although the research and review of manuscripts has increased in recent years, the desired progress has not yet been achieved. This study aims to review and introduce, in terms of the art of illumination, two manuscriptes Juz' of the Qur'an in the Kastamonu Manuscript Library with the inventory numbers 2161 and 2163. These works in the library are remarkable in terms of their illumination characteristics. Similar examples of illuminations seen in the Juz' are seen in illuminations in $16^{\text {th }}$ century manuscripts. Among the illuminations seen in the manuscripts, those at the beginning of Suras and on colophons occupy an important place. In this context, it is seen that the juzs in
\end{abstract}

* Bu makale, Sakarya Üniversitesi Sosyal Bilimler Enstitüsü İslam Tarihi ve Sanatları Ana Sanat Dalında, Doç. Dr. Mehmet Memiş'in danışmanlığında, Yıldırım Karadeniz tarafından hazırlanmakta olan "Süleymaniye, Kastamonu ve Çorum Hasan Paşa Yazma Eserler Kütüphanelerinde Bulunan Bazı Kur'an Cüzlerinin Kitap Sanatları Bakımından İncelenmesi” başlıklı doktora tezinden üretilmiştir.

** Sorumlu Yazar: Yıldırım Karadeniz (Sakarya Üniversitesi Sosyal Bilimler Enstitüsü Doktora Öğrencisi) ve (Öğr. Gör.) Kocaeli Üniversitesi, Güzel Sanatlar Fakültesi, Geleneksel Türk Sanatları Ana Sanat Dalı, Kocaeli, Türkiye.

E-posta: yildirim.karadeniz@kocaeli.edu.tr ORCID: 0000-0001-5214-5242

Atıf: Karadeniz, Yildirim. “Kastamonu Yazma Eserler Kütüphanesinde Bulunan İki Adet Yazma Kur'an-ı Kerim Cüzünün Tezhip Sanat Bakımından Değerlendirilmesi." Art-Sanat, 13 (2020): 245-259.

https://doi.org/10.26650/artsanat.2020.13.0010 
Kastamonu have a very high quality of artistic illuminations and they have not been subject to any research. In this article, the characteristics of the period will be revealed by examining the Juz' in terms of illumination.

Keywords

Kastamonu, Manuscript, Qur'an sections, juz', Qur'an, Illuminated books

\section{Extended Summary}

This article deals with the Qur'an Juz' registered under the inventory numbers 2161 and 2163 in the Kastamonu Manuscript Library. Brief information about the general characteristics of the Juz' is given by explaining the current status of the Juz'. Since the study was on illuminations seen on the Juz', the binding and calligraphical characteristics of the Juz' were not included. However, there is brief information about the binding and calligraphy type of the Juz. The article generally consists of the presentation and analysis of the illuminations on the Juz'. The illuminations on the Juz' are compared with similar examples of the period and information is given about that period.

In this study, the Juz' were examined in terms of illumination characteristics, and the development of the art of illumination through the centuries was explained. The art of illumination has been carried out in different fields of application for centuries, with manuscripts being in the forefront, mostly those of the Holy Quran, and especially those within the Ottoman period. These illuminations, the earliest examples of which are seen in Qur'an manuscripts (half-titles, captions, the beginning of suras, colophons) from the Umayyad and Abbasid periods, have been developed and accessed today showing differences in each period. Many reasons have been given for the extent of the influence of the art of illumination, which has an important place in book arts and has an ancient history. The progress of this decoration style that emerged with the Uighur Turks in Central Asia and has been developing until today is also described. In this article, the stylized floral motifs used as ornamental elements in miniatures depicting the endowing of Manichaeist Uighur monks, which were found in Turfan excavations in Karahoca in Central Asia, and their use in the art of illumination in later periods, is explained. The art of illumination, which reached Anatolia with the Seljuks via Iran and brought with it the remnants of all civilizations that lived here before, continued to develop as the artists transformed these influences into their national tastes. It is possible that influences coming from the Far East and Iran at various intervals had an impact on these developments and styles, and the structures bearing the traces of Mamluk style in many parts of Anatolia were likely to have been built as a result of political and commercial relations. All the social and political changes that Mamluks and Ilkhanians, who had strengthened their military success with art, had undergone for centuries directly or indirectly influenced the culture and art of the 
period of principalities. The clearest examples of this can be seen in the illuminations of the period. The legacy of Anatolian Principalities reached the highest level with new tastes from conquered territories in the $16^{\text {th }}$ century. In terms of the art of illumination in Anatolia, the $16^{\text {th }}$ century was a very productive period compared to the Seljuk period. During this period, illuminated manuscripts were written on religion, history, and physics, especially on the copies of the Qur'an and the works on sufism.

With the regular development of calligraphy in the copies of the Qur'an acquiring artistic qualifications, the first examples of decorations can be seen in the copies from the Late Umayyad-Early Abbasid period between the $8^{\text {th }}$ and $10^{\text {th }}$ centuries. In this research, the illuminations of the Holy Quran are paricularly emphasized to better understand the subject. This study aims to reveal the stylistic features of the manuscripts throughout the centuries and the stylistic differences and similarities in decoration seen from the past to the present are mentioned. When the binding and illumination characteristics of the Juz' in this study are examined, it can be seen that they are in the style of Herat and Shiraz in the Safavid period at the end of the $15^{\text {th }}$ century and the beginning of the $16^{\text {th }}$ century, and this period has been emphasized in this article. In addition, the characteristics of illuminations in the $15^{\text {th }}$ and $16^{\text {th }}$ century manuscripts are explained. The illuminations in the beginning of suras, which were perfected from the $15^{\text {th }}$ century to the second half of the 16 th century, are mostly seen in the copies of the Qur'an written and illuminated in the Iranian region. Illuminations in the beginning of suras, the beginning of the Juz, or on colophons were used in crown, dome, and ink forms. Manuscripts of this period and especially the Safavid period are examined, and an attempt is made to Show the similarities with the juz' which are discussed in the article. The forms seen in the Safavid manuscripts in illuminations in the beginning of suras and on colophons are explained. The illumination characteristics of each work ware analyzed in detail under separate titles. In the part of evaluation of the Juz', we observe that especially the multi-colored style of binding of the Juz' had close similarities with those made in the Safavid period Herat and Shiraz school. The color, pattern designs, and the sheet used in the illuminations on the colophons of the works have a stylistic unity with those seen in the illuminations of the Safavid period manuscripts. The crochets used in the illuminations of the Juz' also reflect the examples of crochets on illuminations from the Safavid period. In the illuminations of between $11^{\text {th }}-14^{\text {th }}$ centuries and the $17^{\text {th }}$ and $18^{\text {th }}$ centuries, the examples of the patterns crocheted directly on drawing rulers with imperfect workmanship were also found. However, in the $16^{\text {th }}$ century, when the art of illumination was at its peak, crochets has crowned illuminations in the beginning of suras, always drawn parallel to the border on the vault with magnificent patterns and craftsmanship.

By way of conclusion, when the illuminations of the Qur'an Juz' with inventory numbers 2161 and 2163 in the Kastamonu Manuscripts Library were considered wit- 
hin the framework of a book arts discipline, it was seen that they were quite artistic and elegant. When the illuminations of the works were examined in terms of color, motif, composition, and craftsmanship, it was noteworthy that they reflected the understanding of art in the illuminations made in the first half of the $16^{\text {th }}$ century, reminding us especially of the illuminations in Safavid writings made in Herat. The use of gold and blue together in the Juz', Hatayi group motifs on very thin branches, sheets with tile red, gold, and black background, especially the floral inside casing on black background seen in the Juz with the inventory number 2163, can be said to be stylistic features of the Safavid period Herat illuminations. Hence, the fine craftsmanship and perfect color harmony seen in the illuminations throughout the $16^{\text {th }}$ century as well as the illumination style of the manuscripts made in Herat in the $16^{\text {th }}$ century are present in these Juz'. Therefore, it was concluded that these Juz' might have been written under the influence of the Herat school in the first half of the $16^{\text {th }}$ century. 


\section{Giriş}

Tezhip, Arapça "Zehep" kelimesinden gelmektedir ve "altınlamak" anlamındadır. Tezhip sanatı farklı uygulama alanlarında kullanılmıştır. Özellikle Osmanlı dönemiyle birlikte el yazmaları, bunların içinde de Kur'an-1 Kerim'ler tezhip sanatının kullanıldığı yerlerin başında gelmektedir. ${ }^{1}$ İlk yazma eserleri M.S. 8. yüzyılda sanat alanında önemli gelişmeler göstermiş olan Uygurlara aittir. M.Ö. 1. yüzyıldan M.S. 13. yüzyıla kadar Orta Asya'da hüküm süren Uygurların duvar resimleri yanında değerli el yazmalarının da olduğu bilinir. Orta Asya'da Uygurlarla ortaya çıkmış olan tezyini motifler, yine Uygurlar aracılığıyla diğer Türk devletlerine geçerek günümüze kadar ilerleyerek gelmiştir. ${ }^{2}$ Orta Asya'da Karahoça' da yapılan Turfan kazılarında bulunan, vakıf yapan Maniheist Uygur Rahiplerinin tasvir edildiği minyatürlerde süsleme ögesi olarak kullanılan stilize edilmiş bitkisel motifler daha sonraki dönemlerde karşımıza çıkan bitki kökenli motiflerin öncüsüdür. ${ }^{3}$

Kur'an-1 Kerim nüshalarındaki, Mushaf hattının düzenli olarak geliştirilmesi ve sanat yönünden de nitelik kazanmasıyla beraber ilk tezyinat örneklerini Geç EmeviErken Abbasi dönemi dediğimiz, VIII.-X. yüzyıllar arasında istinsah edilen Kur'an-1 Kerim nüshalarında görülmektedir.4 "Türk ve İslam Eserleri Müzesi Şam Evrağı belgeleri arasında bulunan bir cüzün tezhipleri ilk örnekler arasında sayılabilir." Selçuklularla İran üzerinden Anadolu'ya ulaşan ve burada daha önce yaşamış tüm medeniyetlerin kalıntılarını taşıyan tezhip sanatı, onu uygulayan sanatkârların bu etkileri kendi millî zevklerine dönüştürmesiyle gelişimini sürdürmüştür. Bu gelişme ve üslupların doğuşunda Uzakdoğu ve İran'dan çeşitli aralıklarla gelen tesirler ${ }^{6}$ etkili olmuştur ve Anadolu'nun pek çok bölgesinde Memlûk üslubundan izler taşıyan yapıların, bu siyasi ve ticari ilişkiler neticesinde inşa edilmiş olması muhtemeldir. Askeri başarılarını sanatla kuvvetlendirmiş olan Memlûklar ile İlhanlıların yüzyıllar içerisinde geçirmiş oldukları tüm sosyal ve siyasal değişimler, Beylikler döneminin kültür ve sanatını dolaylı veya doğrudan etkilemiştir. Bunun en net örnekleri dönemin tezhiplerinde görülmektedir. ${ }^{7}$ Anadolu Beylikler döneminde yapılan tezhipler daha kabadır; münhaniler ve satır aralarında beynesutur bu dönemdeki bezemelerde görülmektedir. ${ }^{8}$

1 İlhan Özkeçeci, Türk Sanatında Tezhip (İstanbul: Yazıgen Yayınevi, 2007), 29-32.

2 Şule Pamuk, “Tezhip,” Klasik Sanatlar Yıllığı 2013 (Ankara: Diyanet İşleri Başkanlığı Yayınları, 2014), 210-211.

3 Faruk Taşkale, "Gelenekten Geleceğe Tezhip Sanatında Bir Yolculuk," El Sanatları Dergisi 9 (2010), 6-7.

4 Ali Fuat Baysal, "Mushaf Tezyinatının Tarih İçindeki Gelişimi," Marife Dini Araştırmalar Dergisi 3 (2010), 366.

5 Zeren Tanındı, "Kur'an-1 Kerim Nüshalarının Ciltleri ve Tezhipleri," 1400. Yllında Kur'an-ı Kerim ( İstanbul: Antik A.Ş. Kültür Yayınları, 2010), 90-121.

6 F. Çiçek Derman, “Tezhip Sanatında Üslûplar ve Sanatkârları,” Türkiye Diyanet Vakfi İslam Ansiklopedisi, c. 41 (İstanbul: TDV Yayınları, 2012), 65-68.

7 Zeynep Demircan Aksoy, “İlhanlı ve Memlûk Etkileşiminde XIV. Yüzyıl Anadolu Türk Tezhip Sanatı,” Uluslararast Sosyal Araştırmalar Dergisi 29 (2014), 266.

8 Pamuk, "Tezhip," 210-211. 
XIV. yüzyıl Anadolu tezhip sanatı bakımından, Selçuklu dönemine göre oldukça verimlidir. Bu dönemde Kur'an-1 Kerim nüshaları ve tasavvuf konulu eserler başta olmak üzere, din, tarih, matematik, fizik, kimya ve aşk konularında tezhipli yazmalar yapılmıştır. ${ }^{9}$ Bunlardan günümüze ulaşan birçok el yazması eser, yurt içi ve yurt dışındaki müze ve koleksiyonlarda bulunmaktadır. Bu nadir ve kıymetli eserler, içerikleriyle dönemin din, bilim ve edebiyat tarihine sşık tutarken, aynı zamanda eserlerin cilt, hat, minyatür ve tezhip özellikleri Anadolu Türk kitap sanatlarının erken dönemleri hakkında önemli bilgiler vermektedir. ${ }^{10}$ Serlevha, unvan sayfası, sure başı tezhipleri Kur'an-1 Kerim tezyinatının ana unsurlarıdır. Bu tezhiplerin boyut ve bezemeleri birbirinden farklı özellikler gösterir. Serlevha tezhibi karşılıklı çift sayfa olarak Fatiha ve Bakara suresine ait ayetleri içerir. Sure başı ise yatay dikdörtgen paftalar halinde olup sureye dair bilgiler, tezhipli alan içerisindeki paftalı alana yazılır. Sure ismi ve numarası yazma geleneğinin bu yüzyıllardan itibaren şekillendiği söylenebilir. "14. yüzyıla gelindiğinde usta sanatçılar tarafından yapılan tasarımlarla büyük boyut tezhip örneklerinin İlhanlı ve Memlûk müzehhipleri tarafından yapılmıştır. Bu tezhip örnekleri Topkapı Sarayı Müzesi Kütüphanesi’nde TSMK. EH.249 envanter numarasına kayıtlı olup tezhiplerini müzehhip Muhammed b. Aybak'n yaptığı Kur'an cüzünde görülmektedir."

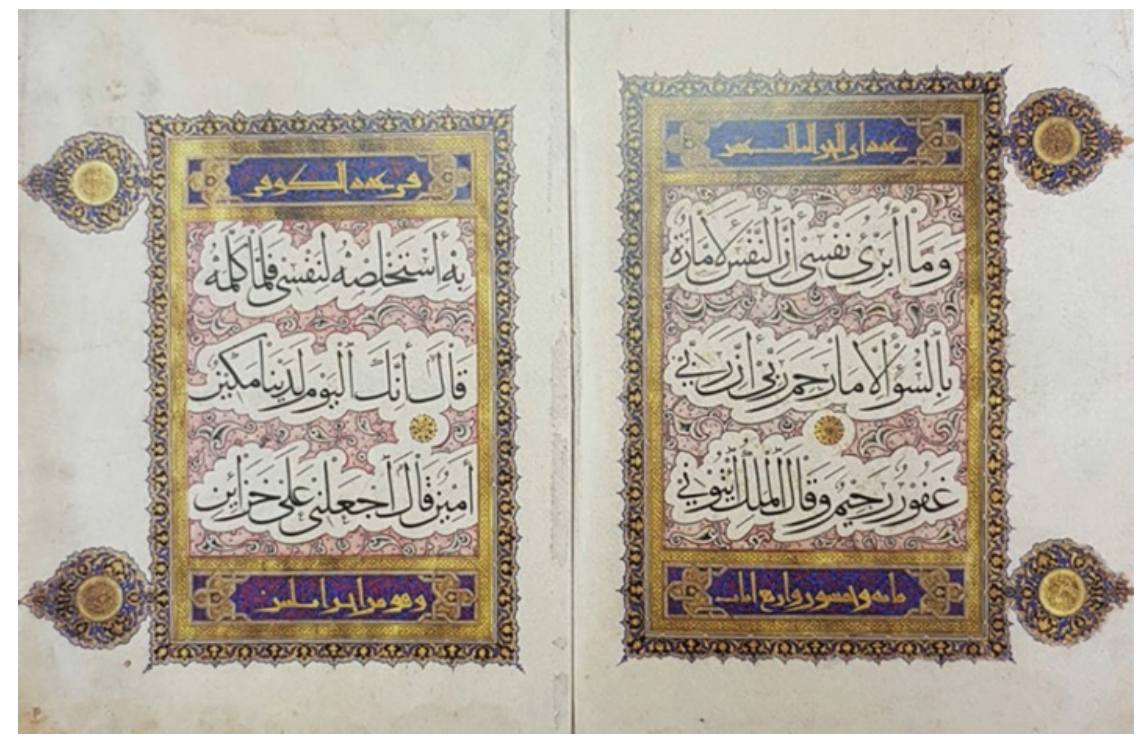

G. 1. Levha tezhip, TSMK. EH.249, 1b-2a., ( Z. Tanınd1, Hat ve Tezhip Sanatı, 2009, 250)

9 Aksoy, "İlhanlı ve Memlûk Etkileşiminde XIV. Yüzyıl Anadolu Türk Tezhip Sanatı," 266.

10 Zeynep Demircan Aksoy, "XIV. Yüzyıl Anadolu Türk Tezhip Sanatı Tasarımları” (Doktora Tezi, Mimar Sinan Güzel Sanatlar Üniversitesi, 2010), 58.

11 Zerrin Tanındı, "Başlangıcından Osmanlıya Tezhip Sanatı," Hat ve Tezhip Sanatı (Ankara: Kültür ve Turizm Bakanlığı Yayınları, 2009), 249-250. 
Dönemin tezhiplerinde görüleceği gibi tezyinatta rumi kompozisyonlar ve ağırlıklı olarak altın kullanılmıştır. Eserlerdeki tezhipli alanlarda, lacivert zemin üzerine altınla rumi kompozisyonlar yapıldığı görülmektedir. Eserlerdeki en önemli özelliklerinden biri de yazı zeminine tezyinat yapılma geleneğidir. Yazı zeminine yapılan tezyinat geleneği Osmanlı klasik döneme kadar hemen hemen tüm serlevha formundaki sure baş1 ve unvan sayfası tezhiplerinde uygulanmıştır. Bu gelenek XV. yüzyılın sonlarına kadar sürmüş, XVI. yüzyıl Osmanlı klasik dönem eserlerinde çok nadir kullanılmıştır. ${ }^{12}$ Makalenin başında değinilen Mushaflardaki bezeme alanlarıyla cüzlerdeki tezhipli alanlar arasında bazı farklılıklar görülmektedir. Cüzlerde, Kur'an-1 Kerimlerdeki serlevha tezhibi yerine cüzün ilk sahifesinde ilahi metnin üst kısmına dolgun bezeme yapılmıştır. Bu alanlara sure başı, cüz başı, fasıl başı veya unvan sahifesi tezhibi denilmektedir. ${ }^{13}$ Sure başı tezhiplerinin sayısı cüzdeki surelerin sayısına bağlıdır. Serlevha ve sure başı tezhibi renk, desen ve motif bakımından zahriye tezhibiyle uyum içinde olmalıdır. ${ }^{14}$ 15. yüzyıl Fatih Sultan Mehmed döneminde yapılan eserlerde çok sık görülen sure başı tezhiplerinde ana zemin rengi olarak kobalt mavisi, altın ve mavinin tonlarının yanı sıra kiremit kırmızısı ve siyah da en çok kullanılan renklerdir. ${ }^{15}$

Osmanlı Tezhip sanatının bir ekol niteliği yansıtan ilk önemli dönemi Fatih Sultan Mehmed'in (1451-1481) saltanat yıllarına rastlamaktadır. Bu döneme ait çok sayıda el yazması eser, başta Topkapı Sarayı ve Süleymaniye Kütüphanesi olmak üzere çeşitli müze ve kütüphanelerde bulunmaktadır. ${ }^{16}$ Fatih, dinî ve ilmî eserleri kendi hususi kütüphanesi için bilinen hattatlara istinsah ettirmiş, yine tanınmış müzehhiplere bu eserlere Selçuklu bezeme üslubundan alınan ilhamla Türk zevkine yakışan bir şekilde tezhip yaptırmıştır. Fatih, bir nakışhâne kurdurmuş, nakışhânenin başına Özbek ası1lı Baba Nakkaş'1 getirmiş ve sarayda güçlü bir sanat merkezi oluşturmuştur. ${ }^{17}$ Fatih devri tezhipleri, Türk tezhip tarihinde tamamen ayrı bir ekolün eserleridir. Bu devrin tezhipleri, özellikle zahriye, temellük, kitabe ve başlık, hatime, yazılı ve yazısız, renkli renksiz halkari metin aralarında, kap ve miklablarda, ayrıca kap içlerinde görülmektedir. ${ }^{18} 15$. yüzyılın ikinci yarında üsluplaştırılmış çiçek motifleri ve renklerdeki zenginlik yaygınlaşmış, taç yapraklar içe kıvrılmış, hatayi motifleri kullanılmış, tığlar sade ve geometrik şekillerden oluşmuştur. ${ }^{19}$ Fatih devri kitap başlıkları devrin tezhip özelliklerine sahip olup mihrap formunda ucu ince tığlarla biten şekillerde

12 Tanındı, "Başlangıcından Osmanlıya Tezhip Sanatı," 243-282.

13 M. Uğur Derman, Doksandokuz İstanbul Mushafi (İstanbul: Türk Petrol Vakfi, 2010), 18.

14 Gülnur Duran, “Serlevha,” TDV İslam Ansiklopedisi, c. 36 (İstanbul: TDV Yayınları, 2009), 567-569.

15 Duran, "Serlevha," 568.

16 Faruk Taşkale, "Tezhip Sanatı ve Tezhip Sanatçısı Rikkat Kunt” (Yüksek Lisans Tezi, Mimar Sinan Üniversitesi, 1990.

17 İsmet Binark, “Tezhip Sanatı ve Kitapçılık Tarihimizde Fatih Devri Tezhipleri,” Türk Kültürünü Araştırma Enstitüsü Türk Kültürü Ayllk Dergisi 75 (1969), 225.

18 Binark, "Tezhip Sanatı ve Kitapçılık Tarihimizde Fatih Devri Tezhipleri," 225.

19 Duran, "Serlevha," 568. 
değil, sayfanın enine uzanan uzun dikdörtgenler şeklinde yapılmıştır. ${ }^{20} 15$. yüzyılda, özellikle Fatih Sultan Mehmed himayesindeki saray nakkaşhânesinde, Türk tezhip üslubu oluşturulmuştur. ${ }^{21} 15$. yüzyıldan 16 . yüzyılın ikinci yarısına kadar en mükemmel hâlini almış olan sure başı tezhipleri daha çok İran bölgesinde yazılıp tezhiplenmiş Mushaflarda görülmektedir. ${ }^{22}$ Sure başı tezhipleri, yazı alanın en üstünde yer alan ve tığlarla neticelenen diş pervaz formuna göre sınıflandırılır. ${ }^{23}$

\section{Envanter Numaralı Kur'an Cüzü Tezhip Özellikleri}

Kastamonu Yazma Eserler Kütüphanesi’nde bulunan 2161 envanter numaralı cüz, $105 \times 150-185 \times 250$ mm ölçülerindedir ve 7 satırdan ve 20 sayfadan oluşmaktadır. Eserin cildi mülemma şeklinde yapılmıştır. Reyhani hattıyla yazılmış olan cüzün üzerinde hattat ismi ve istinsah tarihi yoktur. 2161 envanter numaralı Kur'an-1 Kerim cüzü Bakara suresi 142. ayetten başlayıp 252. ayetle bitmiştir. Yazma eserdeki tek tezhipli bölüm 25b sayfasında görülmektedir. Cüzün unvan sayfa tezhibi yazının hemen üst kısmında dikdörtgen alanda iklil levha formunda tasarlanmıştır. Bu alanın hemen üzerinde bitişik olarak yapılan fakat cetvellerle birbirinden ayrılmış altın cetvelin taç formu bir diğer iklil levha formu cüzün tezhipli sayfasını oluşturmaktadır. Cüzün tezhibi oldukça başarılı ve ince bir işçiliğe sahiptir (G. 2).

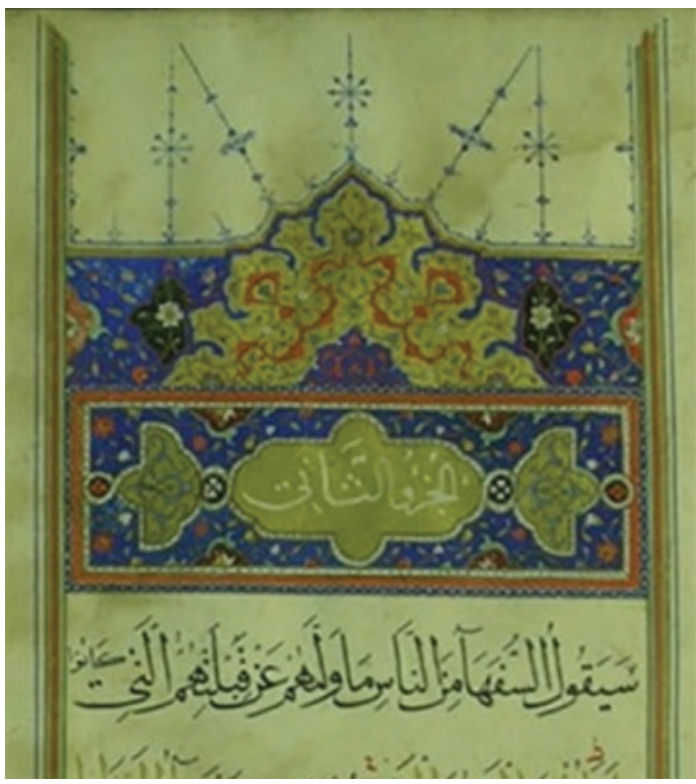

G. 2. Kur'an-1 Kerim cüzünün sure baş1 tezhibi, Kastamonu Yazma Eserler Kütüphanesi / 2161, 25 b.

20 Binark, “Tezhip Sanatı ve Kitapçılık Tarihimizde Fatih Devri Tezhipleri,” 226.

21 Atanur Meriç, “Geleneksel Türk Süsleme Sanatları (Minyatür-Tezhip-Hat),” Vakıf ve Kültür Dergisi 2 (1998), 53-54.

22 Duran, "Serlevha," 568.

23 Baysal, "Mushaf Tezyinatının Tarih İçindeki Gelişimi," 372. 
Dikdörtgen şeklindeki iklil levha formunun ortasında zemini silme altın paftanın sağında ve solunda salbek şekline benzeyen küçük paftalar görülmektedir. Ortadaki paftanın üzerine "üstübeç" denilen beyaz mürekkeple hat yazılmıştır. Bilhassa mushafların sure başlıklarında altın zırnık ${ }^{24}$ yerine üstübeç kullanılmaktadır. Üstübeç mürekkebi de zırnıkla aynı usulle yapılır. ${ }^{25}$ Zemin üstüne beyaz renkle yazı yazılmasında kullanılır. Bunun sebebi muhtemelen hem lâcivert hem de altın zemin üzerinde zer mürekkebe göre daha dikkat çekici bir renk olmasıdır. Bu salbek formuna benzeyen paftaların zeminine de altın sürülerek üzerine açık mavi renkte "çift tahrir" tekniğinde ortabağ ve rumi motiflerinin oluşturduğu $1 / 2$ simetrili desen kompozisyonu yapılmıştır. Paftaların etrafına beyaz iplik üzerine basit zencerek yapılmış, ipliklerin çevrelediği paftalar bu beyaz ipliklerle paftaları birbirine bağlarken dairesel alanlar oluşturmuştur. Dairesel paftaların zemini siyah renkte boyanarak içine beyaz ve turuncu renk penç motifi yapılmıştır (G. 3).

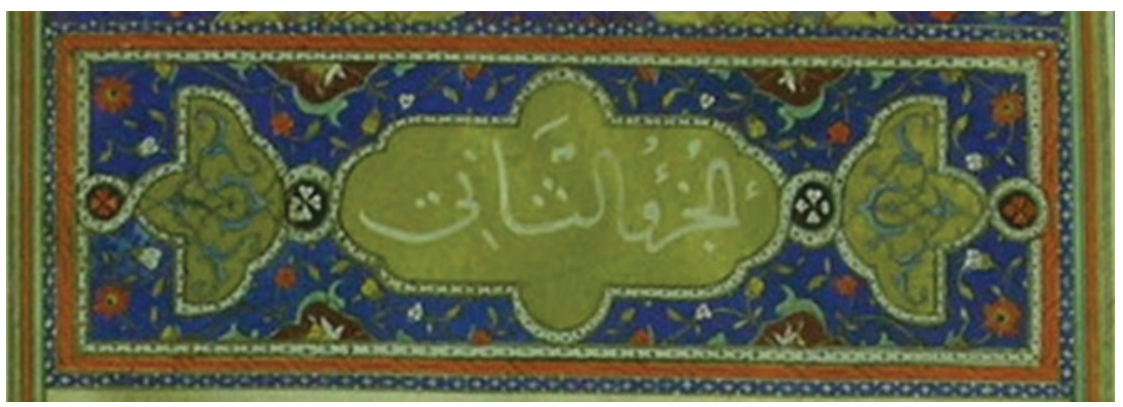

G. 3. Unvan Sayfası tezhibi detayı, Kastamonu Yazma Eserler Kütüphanesi / 2161, 25 b.

İklil sure başı sayfasının ortasındaki paftalı alanlar kitabeli zencereğe benzediği için kitabeli zencerek de denilmektedir. Özellikle kenar bezemelerinde görülen klasik bir üslup olan kitabeli zencerek, daha çok ara suyu olarak yapılmıştır. ${ }^{26}$ Kitabeyi hatırlatan uzun ve büyük olan bu paftalar genellikle tezhipli alanla yazılı alanı birbirinden ayırmak için yapılmıştır ve bu bölümlere "ara suyu" veya "bordür" de denilmektedir. Araştırmalarda, tezyinatta çoğunlukla hatayi ve rumi motifli bağımsız desenlerin yapıldığ $1^{27}$ belirtilmektedir. Ancak nadiren de olsa cilt kapaklarının tezyinatlarında hat yazılmış olan kitabeli zencerekler de görülmektedir.

24 "Zırnık adıyla bilinen tabiattaki arsenik sülfür taşının ezildikten sonra Arap zamkı mahlûlü ile karıştırılmasıyla sarı renkli, ancak çabuk solan bu mürekkep elde edilir. Bunun turuncu renkli bir cinsi de altınbaş zırnı̆̆ 1 adıyla bilinir, ondan da mürekkep yapılır. Zırnık mürekkeb celî hatların kalıplarını yazmakta kullanılır." Bkz. Uğur Derman, "Mürekkep," Türkiye Diyanet Vakfi İslam Ansiklopedisi, c. 32, (İstanbul: Diyanet Vakfi Yayınları, 2006), 46-47.

25 Uğur Derman, "Mürekkep," 46-47.

26 İnci A. Birol, Türk Tezyini Sanatlarında Desen Tasarımı ( İstanbul: Kubbealtı Neşriyat, 2017), 196. Bkz. Birol, “Türk Tezhip Sanatında Desen,” Hat ve Tezhip Sanatı (Ankara: Kültür ve Turizm Bakanlığı Yayınları, 2009), 489-502.

27 Birol, Türk Tezyini Sanatlarında Desen Tasarımı, 196. 
İklil formunda yapılan sure başı tezhipli bölümün paftalı alanının dışına mavi renk üzerine hatayi rubu motiflerin ve yaprakların oluşturduğu $1 / 2$ simetrili kompozisyon tasarlanmıştır. Hatayi grubu motifler, kiremit kırmızı, beyaz ve sarı renkte boyanarak altın dallar ve yapraklar çift tahrir tekniğinde yapılmıştır. Özellikle 16. yüzyılda yapılan tezhiplerin karakteristik özelliği olan çok ince dallar ve kaliteli işçilik burada da görülmektedir. İklil levhanın uzun kenarlarında cetvele bitişik rumi motifiyle oluşturulan su yeşilinde iplik paftalar yapılmıştır. Paftaların zemini kiremit kırmızısı renginde boyanarak üzerlerine çift tahrir tekniğinde hatayi grubu motifler uygulanmıştır. İklil levha formunda yapılan alan beyaz, turuncu ve mavi renk olmak üzere yaklaşı 2 mm'lik cetvellerle son bulmuştur. Cetvellerden beyaz ve mavi renkte olanların üzerine basit zencerek yapılmış, turuncu olanaysa bunlardan farklı olarak tekli (tek sıra tam noktalı) zencerek ara suyu deseni çizilmiştir. ${ }^{28}$

Cüzün (25b) unvan sayfasının taç şeklinde iklil levha formundaki alanındaysa ikinci tezhip üslubu olan, zeminleri altın ve renkle boyanmış rumi, hatayi, yaprak motifleri ve dendanlarla paftalar oluşturulan simetrik kompozisyonlar yapılmıştır. ${ }^{29}$ Beyaz ipliklerin dendanlarla oluşturduğu paftalı bölüm içinde altın zemin üzerinde hatayi grubu motifler çini bulutlarıyla ${ }^{30}$ birlikte $1 / 2$ simetrik desen tasarımı oluşturmaktadır. Kompozsiyon içindeki yapraklar ve dallar altınla çift tahrir tekniğinde yapılmıştır. Tığların olduğu iklil levha formundaki dikdörtgen alan üzerinde kubbe formun sağında ve solunda salbek şekline benzeyen iplik paftalar görülmektedir. ${ }^{31}$ Paftaların zemini siyah renkte boyanmış, üzerinde beyaz renkte hatayi ve yaprak motifler çift tahrir tekniğinde yapılmıştır. Dikdörtgen formun kısa kenarlarında su yeşili renginde rumi motifiyle oluşturulan yarım paftaların turuncu renk zemini üzerine beyaz renkte hatayi motifi çizilmiştir. Paftaların dışındaki alanın zemini mavi renkte boyanarak üzerine S kıvrımlı tek dal iplik üzerinde yaprak ve hatayi grubu motiflerle serbest kompozisyon tasarlanmıştır. Sure başı tezhibi lacivert kuzu üzerine yapılan tığlarla son bulmuştur (G. 4).

28 Birol, Türk Tezyini Sanatlarında Desen Tasarımı, 239-240.

29 Gül Güney, "Manisa İl Halk Kütüphanesi 3136 Env. No'lu "Mushaf-I Şerif'in Tezhip Bakımından Değerlendirilmesi," Sanat Dergisi 19 (2011), 29.

30 Motif Simurg ve Ejderhaların boğuşması sırasında, hırs ve gazap hâli olarak burunlarından çıkan buharın ifadesi veya tabiattaki bulutların üsluplaştırılmasıyla çizilen münhani şekillerden meydana gelmektedir. Türklerde ise bulut motifinin çıkış noktası tabiattır. Özellikle Türk sanatında 15. yüzyıldan sonra önemli bir yere sahip olan motif 15. yüzyılda Herat ve Şiraz ekolünde sıkça kullanılmıştır. Türk sanatına Osmanlılar döneminde Timurlularla olan ilişkiler neticesinde Herat, Şiraz veya Tebriz ekolüyle gelmesi muhtemeldir. Bulut motifinin en parlak devri 16. yüzyılın ikinci yarısında İznik çinilerinde ve Osmanlı Saray Nakkaşhanesi’nin kitap ciltlerinde ve tezhiplerinde görülmektedir. Sonuç olarak en güzel klasik örnekleri 16. yüzy1lın ikinci yarısında verilmiş olan motif, aynı zamanda birçok alanda uygulanmış, özellikle Osmanlı İznik çinilerinde en parlak devrini yaşamıştır. Bkz. Abdulkadir Yılmaz, Türk Kitap Sanatları Tabir ve Istılahları (İstanbul: Damla Yayınevi 2004), 33-34; Ayrıca bkz. Aziz Doğanay, "Bulut Motifi," Hat ve Tezhip Sanatı, Ed. Ali Rıza Özcan (Ankara: Kültür ve Turizm Bakanlığı Yayınları, 2009), 467.

31 Güney, "Manisa İl Halk Kütüphanesi 3136 Env. No'lu "Mushaf-I Şerif'in Tezhip Bakımından Değerlendirilmesi," 29. 


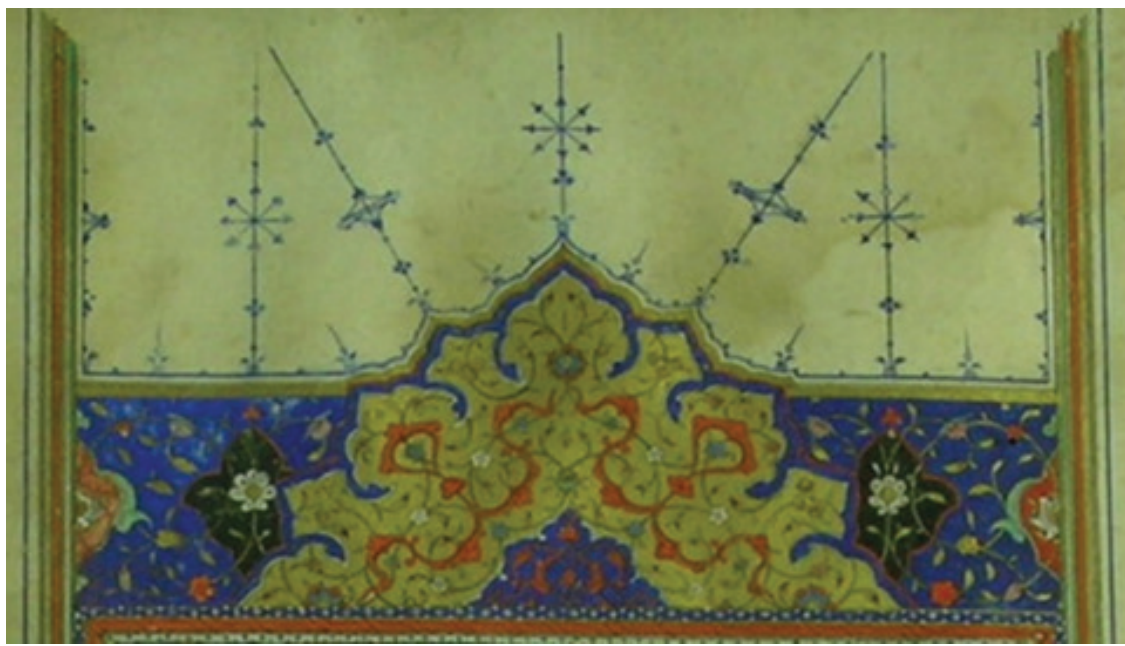

G. 4. Unvan Sayfası tezhibi detayı, Kastamonu Yazma Eserler Kütüphanesi / 2161, 25b.

\section{Envanter Numaralı Kur’an-ı Kerim Cüzünün Tezhip Özellikleri}

Kastaтопи Yazma Eserler Kütüphanesi'nde bulunan, 2163 envanter numaralı Kur'an-1 Kerim, 105x150 ve 185x250 mm boyutunda, reyhani hattıyla yazılmış olup satır sayısı yedidir. Makalede ele alınan aynı kütüphanedeki 2161 envanter numaralı cüzün cilt ve yazı özellikleriyle aynıdır. 2163 envanter numaralı cüz Nisa suresi 148. ayetle başlayıp Maide suresi 82. ayetle bitmektedir. Bu cüzün unvan sayfa tezhibi de yukarda ele alınan cüzle benzer özellikler göstermektedir. Unvan sayfası tezhibini yukardakinden ayıran en temel fark taç formunda yapılmamış olmasıdır. İklil formunda yapılmış olan tezhibin zemini mavi olup $1 \frac{1}{2}$ simetrik kompozisyon özelliği göstermektedir. Turuncu ipliklerle oluşturulan paftalı alanların zeminine parlak sarı altın sürülerek üzerine açık mavi ve turuncu renk hatayi grubu motifler ile çift tahrir tekniğinde yapılan altın dallar ve yapraklar çizilmiştir. Ortadaki büyük paftalı alan içine beyaz mürekkeple cüzün numarası sülüs hatla yazılmış ve zeminine herhangi bir süsleme yapılmamıştır. Yazı zemininde tezyinatın yapılmaması özellikle XVI. yüzyıl eserlerinde görülmektedir. İklil levha tezhibi renk, kompozisyon ve işçilik bakımından oldukça niteliklidir. Tezhip deseni $1 / 2$ simetrik kompozisyon özelliği göstermektedir. Tezyinatlı alanın zemini Osmanlı döneminin klasik zemin rengi olan mavi renkte boyanmıştır. Eserin unvan sayfa tezhibinde görülen bir diğer iklil levha formu da 1/2 simetrik kompozisyonlu olup mavi zemin üzerine hatayi gurubu motiflerin oluşturduğu desen tasarımıdır. Mavi zemin üzerinde turuncu ipliklerin oluşturduğu salbek formundaki altın zeminli paftalar görülmektedir. Altın zeminler üzerine açık mavi ve açık pembe renkte boyanan hatayi motifi, çift tahrir tekniğinde altın dal ve yapraklarla birlikte kompozisyon oluşturur. Diğer paftalı alansa su yeşili renginde rumi motifinden oluştuğu ve zemini kiremit kırmızısı alanın hatayi grubu motifler ve altın dallarla 
bezendiği görülmektedir. Paftalı alanların dışında kalan bölümde mavi zemin üzerine hatayi grubu motifler kademeli olarak beyaz, kırmızı, sarı ve pembe renkte boyanmış ve yaprak ve altın dallarla kompozisyon oluşturulmuştur. İklil levha formundaki tezhipli alanların etrafını çevreleyen altın, açık yeşil, turuncu renk cetveller çekilmiş, iç ve dış cetveller arasına yaklaşık $5 \mathrm{~mm}$ kalınlığında siyah zeminli bordür yapılmıştır. Bordürün içi altın renkte tek dal iplik üzerine hatayi grubu motifler, kırmızı, beyaz, sarı, pembe renkte kademeli boyanarak serbest desen özelliği kazandırılmıştır. Eserin sure başı tezhibi lacivert kuzu üzerinde tığlar yapılarak sonlandırılmıştır. Tığlar tezhiplerle aynı dönemi yansıtmaktadır (G. 5).

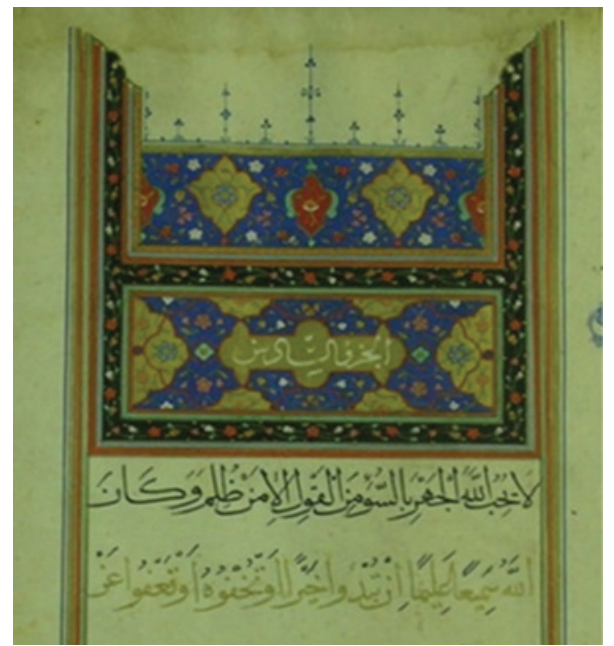

G. 5. Unvan Sayfası tezhibi detayı, Kastamonu Yazma Eserler Kütüphanesi / 2163, 4b.

\section{Değerlendirme}

2161 envanter numaralı cüzün tezhip özellikleri incelendiğinde özellikle mülemma tarzdaki cildin Safevi dönemi Herat Şiraz ekolünde yapılanlarla benzerlikler gösterdiği görülmüştür. Eserin unvan sayfa tezhibinde görülen paftalama şekli göz önüne alındığında cüzün, Safevi dönemi yazma eserlerin tezhiplerinde görülen paftalama üslubunu yansıttığı söylenebilir. Cüzün tığları da eserin dönemi hakkında ipuçları vermektedir. Yine cüz Safevi dönemi tezhiplerinde görülen tığ örneklerini yansıtmaktadır. Tığlar, 11-14. yüzyıllar arasındaki ve 17-18. yüzyıllara ait tezhiplerde, tığların doğrudan cetvel üzerine işlenmiş deseni ve işçiliği mükemmel olmayan örneklerine de rastlanmaktadır. ${ }^{32}$ Halbuki tezhip sanatının zirvede olduğu 16. yüzyılda tığlar, daima sınıra paralel çizilen kuzu üzerinde yer almış muhteşem desen ve işçiliğiyle sure başı tezhiplerine taç olmuştur. ${ }^{33}$ Cüzün tığlarına bakıldığında 16. yüzyıldaki tığları yansittığ söylenebilir. 
2163 envanter numaralı el yazması cüzün, tezhip özelliklerine ve sayfa düzenine bakıldığında 2161 envanter numaralı cüzle aynı üsluba sahip olduğu, muhtemelen aynı dönemde, hatta aynı atölyede farklı sanatçılar tarafından yapıldığı söylenebilir. Cüzün tezhipleri oldukça kalitelidir. Tezhiplerin 16. yüzyılda Herat’ta yapılan yazmaların süsleme üslubunu hatırlatması, cüzün serin saray atölyelerinde bu ekolün etkisi altında yapılmış olduğunu göstermektedir. Özellikle eserin tığlarının 2161 envanter numaralı cüzün tığlarıyla aynı özellikleri yansıtması iki cüzünde aynı dönemde yapılmış olabileceğini düşündürmektedir. El yazması Mushaf cüzü benzer örneklerle karŞılaştırıldığında cilt ve tezhip özellikleri, yapılan işçilik ve sayfa düzeni bakımından 16. yüzyılda Herat’ta yapılanlarla benzer özelliklere sahip olduğu sonucuna varılabilir.

\section{Sonuç}

Kastamonu Yazma Eserler Kütüphanesi'nde bulunan 2161 ile 2163 envanter numaralı Kur'an-1 Kerim cüzlerinin tezhipleri kitap sanatları disiplini içerisinde ele alındığında oldukça sanatsal ve zarif eserler olduğu görülmüştür. Eserlerin istinsah kaydının olmaması cüzlerin tarihlendirilmesi konusunda zorluklar yaratmaktadır. Tezhip özellikleri kesin bir tarih ortaya koymasa da cüzlerin yakın bir tarihte hazırlandığının tespitinde yardımcı olmuştur. İnce bir işçiliğe sahip olan cüzlerin sayfa düzeni, kullanılan renkler, motif ve kompozisyonlar Herat'ta yapılmış Safevi dönemi yazmalarını hatırlatmaktadır. Bu nedenle tezhip özelliklerine bakarak cüzlerin 16. yüzyılın başı Safevi Herat etkisinde yapılmış olabilecekleri kuvvetle muhtemeldir.

"Safevilerdeki kitap sanatları örnekleri Osmanlılarda olduğu gibi sadece sarayda yapılanlarla sınırlı kalmamış sanatçıların Herat, Şiraz ve Tebriz gibi şehirler arasında gidip gelerek çalışmalarının yanı sıra Osmanlı saray atölyelerine giderek buradaki sanatçıları da etkilemişlerdir." ${ }^{34}$ Bu etkileşim saray nakkaşhânelerinde yapılan eserlerin tezhiplerinde ortaya çıkmıştır. Makalede ele alınan cüzlerin unvan sayfası, tezhiplerinde görülen altın ve mavinin yoğun şekilde bir arada kullanılması ve tezhiplerdeki paftalama şekli Safevi dönemi Herat tezhiplerinin üslup özelliklerindendir. Bu üslup benzerliği eserlerin aynı dönemde yapılmış olma ihtimalini güçlendirmektedir. Bu dönemdeki eserlerin tezhiplerinde kompozisyon ve işçilik yönünden bazı farklılıklar görülmektedir. Bunun sebebi Osmanlı dönemindeki nakkaşhâne geleneğinden kaynaklanmaktadır. Çünkü özellikle Osmanlılarda Fatih Sultan Mehmed, II. Bayezid, Yavuz Sultan Selim ve Kanuni Sultan Süleyman'ın saltanat yıllarında nakkaşhâneler güçlenerek tezyini sanatlarda merkezi bir konuma ulaşmıştır. ${ }^{35}$ Bu nedenle, yazma eserler tezhip özellikleri bakımından benzer ve farklı özellikler gösteren eserlerin aynı dönemde, hem aynı hem de farklı nakkaşhânelerde yapılabileceğini gösterebilir.

34 Güney, "Manisa İl Halk Kütüphanesi 3136 Env. No'lu "Mushaf-I Şerif'in Tezhip Bakımından Değerlendirilmesi," 30.

35 Birol, Türk Tezyini Sanatlarında Desen Tasarımı, 42. 
Makalede ele alınan cüzlerin tezhipleri detaylı bir şekilde incelendiğinde yukarıda da belirtildiği gibi sayfa düzeni, kullanılan renkler, motifler ve paftalar bakımından benzerliklerin yanı sıra işçilik ve kompozisyon bakımından farklılıkların görülmesi, tezhiplerin bir kalıptan ve aynı müzehhip tarafindan yapılmadığını göstermektedir. Kur'an-1 Kerim cüzlerindeki bezemelerde görülen benzerlik dikkat çekicidir. Bu yüzden cüzlerin aynı nakkaşhânede yapıldıkları ve üslup birliğinin olduğu görülmüştür.

Sonuç olarak eserlerde altın ve mavinin birlikte kullanılması, ince dallar üzerinde sıralanan hatayi grubu motifler, kiremit kırmızısı, altın ve siyah zeminli paftalar, özellikle 2163 envanter numaralı cüzde görülen siyah zeminli çiçekli iç pervaz, Safevi dönemi Herat tezhiplerinin üslup özelliklerindendir. Bu nedenle tezhipler 16. yüzyılda Herat'ta yapılan eserlerin tezhip üslubunu yansıttığı söylenebilir. Ayrıca Osmanlı klasik dönem eserlerinde görülen ince işçilik ve mükemmel renk uyumunun bu eserlerde de görülüyor olması cüzlerin bu dönemde yapılmış olabileceği fikrini güçlendirmektedir.

Hakem Değerlendirmesi: Dış bağımsız.

Çıkar Çatışması: Yazar çıkar çatışması bildirmemiştir.

Finansal Destek: Yazar bu çalışma için finansal destek almadığını beyan etmiştir.

Peer-review: Externally peer-reviewed.

Conflict of Interest: The author has no conflict of interest to declare.

Grant Support: The author declared that this study has received no financial support.

\section{Kaynakça/References}

Algaç, Şeyda. “Anadolu Selçukluları ve Beylikleri Dönemi Tezhip Sanatı.” Doktora Tezi, İstanbul Üniversitesi, 2000.

Baysal, Ali Fuat. "Mushaf Tezyinatının Tarih İçindeki Gelişimi.” Marife Dini Araştırmalar Dergisi 3 (2010): 365-386.

Binark, İsmet. “Tezhib Sanatı ve Kitapçı1lı Tarihimizde Fatih Devri Tezhipleri.” Türk Kültürünü Araştırma Enstitüsü Türk Kültürü Aylık Dergisi 75 (1969): 220-233.

Birol, İnci. "Türk Tezhip Sanatında Desen,” Hat ve Tezhip Sanatı. Ankara: Kültür ve Turizm Bakanlığı Yayınları, 2009, 489-502.

Birol, İnci. Türk Tezyini Sanatlarında Desen Tasarımı. İstanbul: Kubbealtı Neşriyat, 2017.

Boydak, Fatma Şeyda. "Rodos Fethi Paşa Vakfı Hâfız Ahmet Ağâ Kütüphanesi’nde Bulunan XVI. Yüzyıla Ait Bazı Yazma Eserlerdeki Unvân Sayfası Tezhipleri.” İstem 26 (2015): 73-93.

Bolat, Songül. "Hacı Selim Ağa Kütüphanesi Yazmalarının Tezhip Sanatı Açısından Tanıtılması." Yüksek Lisans Tezi, Fatih Sultan Mehmet Vakıf Üniversitesi, 2014.

Derman, F. Çiçek. “Tezhip Sanatında Üslûplar ve Sanatkârları.” Türkiye Diyanet Vakfi İslam Ansiklopedisi. 41. İstanbul: Diyanet Vakf1 Yayınları, 2012, 65-68.

Derman, M. Uğur, Doksandokuz İstanbul Mushafi. İstanbul: Türk Petrol Vakfi, 2010.

Derman, M. Uğur. “Mürekkep,” Türkiye Diyanet Vakfi İslam Ansiklopedisi. 32. İstanbul: Diyanet Vakfi Yayınları, 2006, 46-47. 
Demiriz, Yı1dız. “16. Yüzyıla Ait Tezhipli Bir Kur’an.” İstanbul Üniversitesi Sanat Tarihi Yıllı̆̆ 7 (1977): 41-58.

Demircan Aksoy, Zeynep. “XIV. Yüzyıl Anadolu Türk Tezhip Sanatı Tasarımları.” Doktora Tezi, Mimar Sinan Güzel Sanatlar Üniversitesi, 2010.

Demircan Aksoy, Zeynep. "İlhanlı ve Memlûk Etkileşiminde XIV. Yüzyıl Anadolu Türk Tezhip Sanatı.” Uluslararası Sosyal Araştırmalar Dergisi 29 (2014): 266-280.

Duran, Gülnur. "Serlevha.” Türkiye Diyanet Vakfi İslam Ansiklopedisi. 36. İstanbul: TDV Yayınlar1, 2009, 567-569.

Doğanay, Aziz. "Bulut Motifi." Hat ve Tezhip Sanatı. Ankara: Kültür ve Turizm Bakanlığı Yayınları, 2009, 467-478.

Demiriz, Yıldız. “16. Yüzyı1 Kur’an Tezhipleri Hakkında Bazı Notlar.” Sanat Tarihi Yıllı̆̆ XIII Ord. Prof. Dr. Mazhar Şevket Ípşiroğlu Özel Sayısı (1988): 63-90.

Güney, Gül. “Manisa İl Halk Kütüphanesi 3136 Env. No'lu “Mushaf-I Şerif'in Tezhip Bakımından Değerlendirilmesi." Sanat Dergisi 19 (2011): 25-40.

Güney, Gül. "Memlük Dönemi Müzehhibi Ebu Bekir'e Atf Edilen Tezyinat Üslubuna İlişkin Bir Değerlendirme.” Uluslararası Sosyal Araştırmalar Dergisi 28 (2013): 130-137.

Güney, Gül. "Safevi-Şiraz Dönemi Özelliği Gösteren Bazı Kur'an-1 Kerim Nüshalarının Serlevha Tezhipleri." Akademik Sosyal Araştırmalar Dergisi 43 (2017): 133-153.

Uluç, Lale. XVI. Yüzyıl Şiraz El Yazmaları. İstanbul: Türkiye İş Bankası Kültür Yayınları, 2006.

Pamuk Şule. “Tezhip.” Klasik Sanatlar Yıllığı 2013. Ankara: Diyanet İşleri Başkanlığı Yayınları, 2014, 210-211.

Meriç, Atanur. “Geleneksel Türk Süsleme Sanatları (Minyatür-Tezhip-Hat).” Vakıf ve Kültür Dergisi 2 (1998): 52-54.

Özkeçeci, İlhan. Türk Sanatında Tezhip. İstanbul: Yazıgen Yayınevi, 2007.

Songül, Bolat. "Hacı Selim Ağa Kütüphanesi Yazmalarının Tezhip Sanatı Açısından Tanıtılması.” Yüksek Lisans Tezi, Fatih Sultan Mehmet Üniversitesi Vakıf Üniversitesi, 2014.

Taşkale, Faruk. "Gelenekten Geleceğe Tezhip Sanatında Bir Yolculuk.” İstanbul Büyükşehir Belediyesi Sanat ve Meslek Eğitim Kursları El Sanatları Dergisi 9 ( 2010): 6-19.

Taşkale, Faruk. “Tezhip Sanatı ve Tezhip Sanatçısı Rikkat Kunt.” Yüksek Lisans Tezi, Mimar Sinan Güzel Sanatlar Üniversitesi, 1990.

Tanındı, Zeren. "Kur'an-1 Kerim Nüshalarının Ciltleri ve Tezhipleri.” 1400. Yılında Kur'an-ı Kerim. İstanbul: Antik A.Ş. Kültür Yayınları, 2010, 90-121.

Tanındı, Zeren, "Başlangıcından Osmanlıya Tezhip Sanatı." Hat ve Tezhip Sanatı. Ankara: Kültür ve Turizm Bakanlığı Yayınları, 2009, 243-282.

Tanrıver Celasin, Ayşe. “Tezhip Sanatında Emevî Dönemi Sûrebaşı Bezemelerinin Yeri.” Süleyman Demirel Üniversitesi Güzel Sanatlar Fakültesi Hakemli Dergisi 12 (2013): 120-138.

Tanrıver Celasin, Ayşe. "XV-XVI. Yüzyıl Osmanlı Tezhip Sanatı Bağlamında Şeyh Hamdullah Mushafları Sûrebaşı Bezemelerinin Değerlendirilmesi.” Doktora Tezi, Süleyman Demirel Üniversitesi, 2014.

Yılmaz, Abdulkadir. Türk Kitap Sanatları Tabir ve Istılahları. İstanbul: Damla Yayınevi 2004. 
